\title{
COMENTÁRIO EDITORIAL
}

\section{O PROCESSO EDITORIAL: DA SUBMISSÃO À REJEIÇÃO (OU ACEITE)}

\author{
Manuel Aníbal Silva Portugal Vasconcelos Ferreira \\ Editor Adjunto RIAE \\ Universidade Nove de Julho - UNINOVE \\ Programa de Pós-Graduação em Administração
}

As universidades exigem aos Professores a realização de pesquisa, e subsequente publicação, como parte das suas obrigações e, em certos casos, do seu próprio contrato de trabalho. A publicação de artigos em periódicos de elevado status é necessária para a manutenção do emprego e progressão na carreira, para a mobilidade interinstitucional dos professores, para a satisfação individual, para captar atenção e prestígio. Para as universidades o histórico de publicações contribui para a capacidade de atração de novos professores, de alunos de Mestrado e Doutorado e mesmo para a captação de fundos para mais pesquisas e modernização. Assim, a publicação em periódicos com revisão é um requisito (Hojat, Gonnella e Caelleigh 2003) que se vai aprofundando na necessidade, e benefícios, de não apenas publicar, mas publicar em periódicos de maior reputação. No entanto há barreiras. Há as individuais, nas lacunas de conhecimento ou mestria de técnicas específicas mas há também todo o processo editorial onde editores e revisores são usualmente referimos como os gatekeepers do conhecimento (Beyer, Chanove \& Fox, 1995; Hojat, Gonnella, \& Caelleigh, 2003).

Represento o processo editorial e de publicação na figura 1, seguindo a proposta de van Wyk (1998) que analisou o que designou por publicar como um sistema. É um sistema com os seus componentes: autores, revisores, editores, leitores e comunidade, com um processo, com objetivo (o de geração de conhecimento, de aprendizagem), um sistema de recompensas sociais e materiais para o pesquisador e para a Universidade de acolhimento. 
O Processo Editorial: da Submissão à Rejeição (ou Aceite)

Figura 1- Publicar como um sistema

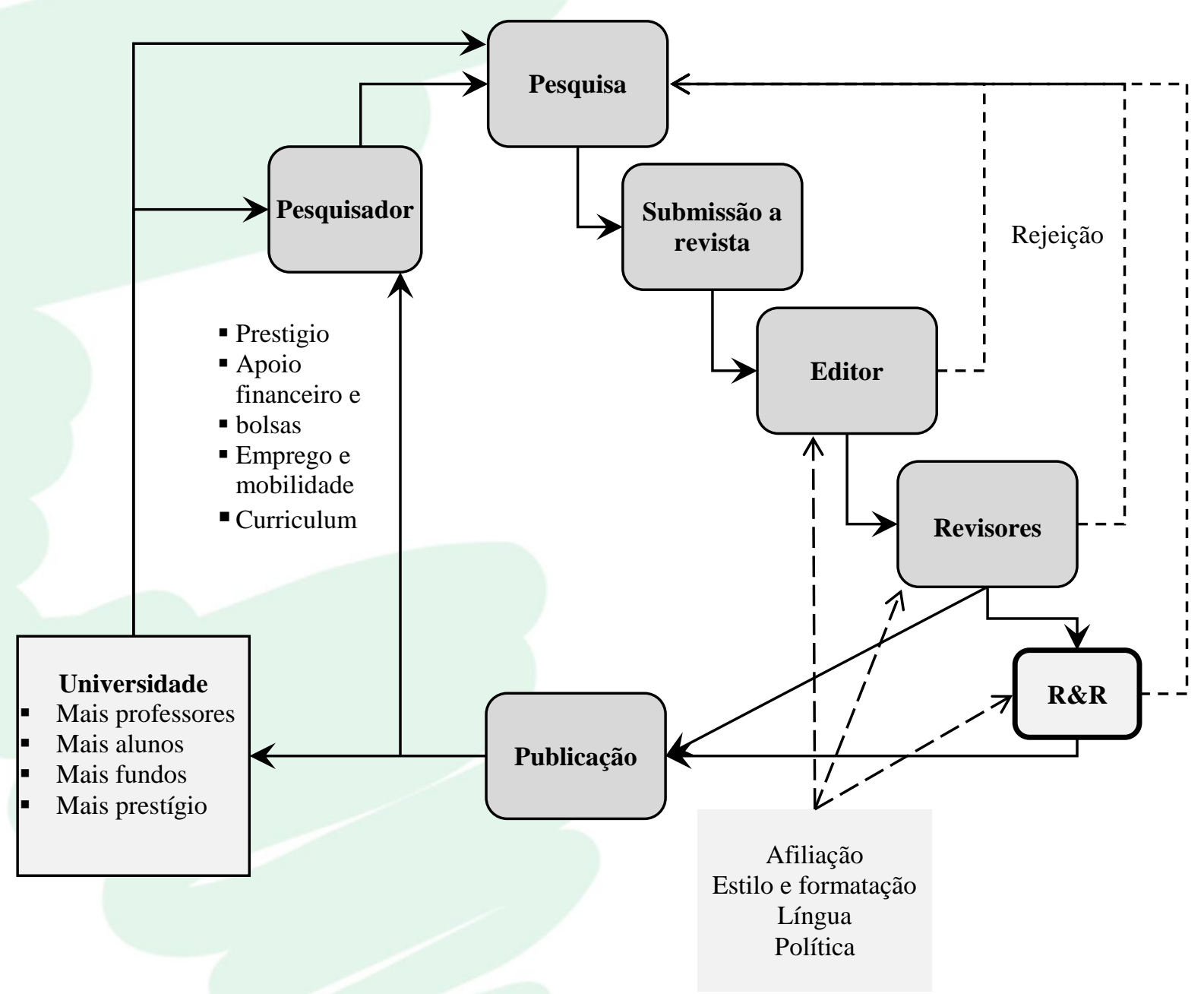

Fonte: Adaptado de Van Wyk (1998) Publish or perish: A system and a mess. System Practice and Action Research, 11(3): 247-259, 1998.

A área de Administração não é diferente, pelo que importa entender, neste comentário editorial, como se desenvolve o processo de submissão e possíveis resultados. Certamente são do conhecimento os inúmeros casos de insucessos (ou aparentes insucessos) do sistema, onde artigos que viriam a tornar-se referências do conhecimento em áreas específicas foram rejeitados diversas vezes antes de serem publicados (ver, por exemplo, Shugan, 2002, 2007). Embora existam imensos casos, vale recordar as rejeições do artigo de Akerlof, prêmio Nobel, onde desenvolve a idéia de "market for lemons", que foi rejeitado de periódicos como a American Economic Review, Journal of Political Economy e Review of Economic Studies com alegações da sua trivialidade. Portanto, a assunção que o processo é perfeito e os editores e revisores são absolutos conhecedores é falaciosa. 
Há disfunções no processo (Starbuck 2005), mas é possível aprender e melhorar. Este editorial também tem o objetivo de contribuir para melhor entendermos todo o processo, ou sistema. Esta melhoria envolve questionar porque estes manuscritos que deviam ser publicados são aceites, e porque outros que deviam ser rejeitados são aceites (Shugan, 2007).

\section{AS ETAPAS DA SUBMISSÃO A UM PERIÓDICO}

Antes de submeter o seu artigo a um periódico sugiro que siga as seguintes etapas. Primeira, analise o Qualis e a classificação de cada periódico. Periódicos melhor classificados não apenas pontuam mais mas induzem maior prestígio e notoriedade. No entanto, é preciso seguir para a segunda etapa, analisar a qualidade do seu artigo e escolher o periódico de acordo. Provavelmente não será racional enviar um artigo de média qualidade para um periódico de alta classificação. Terceira, escolhido o periódico verifique se cumpre todas as normas relativas à identificação de autores, resumo, formatação de títulos e subtítulos e de inserção de figuras e tabelas e as referências. Uma vez submetido o artigo espere pela resposta do editor e/ou revisores antes de eventuais alterações ou da submissão a outro periódico. Não pode, pelas normas, submeter simultaneamente um artigo a vários periódicos. Assim, o processo começa na escrita do artigo e na escolha do periódico onde submeter (van Teijlingen \& Hundley, 2002).

Muitos alunos e acadêmicos mais jovens não sabem como se desenrola o processo de submissão. Acompanhe a explicação com a representação das etapas na figura 2. Quando o autor submete um manuscrito para eventual publicação, o editor faz uma avaliação preliminar do manuscrito quanto à qualidade geral, contribuição, adequação à revista, qualidade da escrita, etc. (van Teijlingen \& Hundley 2002; Tight, 2003; Clark, Floyd \& Wright, 2006). Em alguns casos a avaliação pelo editor é acompanhada por uma análise pelos serviços de apoio que confirmam a formatação do artigo e o cumprimento das normas, nomeadamente formatação das referências. Este processo de análise prévia pelo Editor pode ter um dos seguintes desfechos. O primeiro é o Editor aceitar o artigo para publicação, o que raramente ocorre nesta fase e motivo pelo que recomendo: celebre o sucesso!

Há algumas idéias preconcebidas e algum mistério envolvendo o processo de publicação e o que se passa dentro dos periódicos (Beyer, Chanove \& Fox, 1995). Alguns pensam que o objetivo e função primeira do Editor e revisores é rejeitar todos os artigos, exceto os melhores. Na realidade, embora o Editor tenha um papel ativo no processo - que esperamos seja o menos enviesado 
O Processo Editorial: da Submissão à Rejeição (ou Aceite)

possível nomeadamente por autores que conhece, pelas suas preferências teóricas e metodológicas são os revisores os principais atores no processo (Beyer, Chanove \& Fox, 1995; Shugan, 2007). A função primeira do Editor é garantir que consegue fechar o número no prazo estipulado, para o que precisa atrair e manter no processo um conjunto de artigos que consiga sobreviver ao processo e possa publicar. Objetivamente, nos periódicos mais reputados a tarefa é simplificada porque estes já atraem os melhores artigos. Nos periódicos menos cotados, a tarefa maior é atrair artigos e zelar pelo bom desenrolar do processo editorial.

Figura 2 - Etapas do processo de submissão

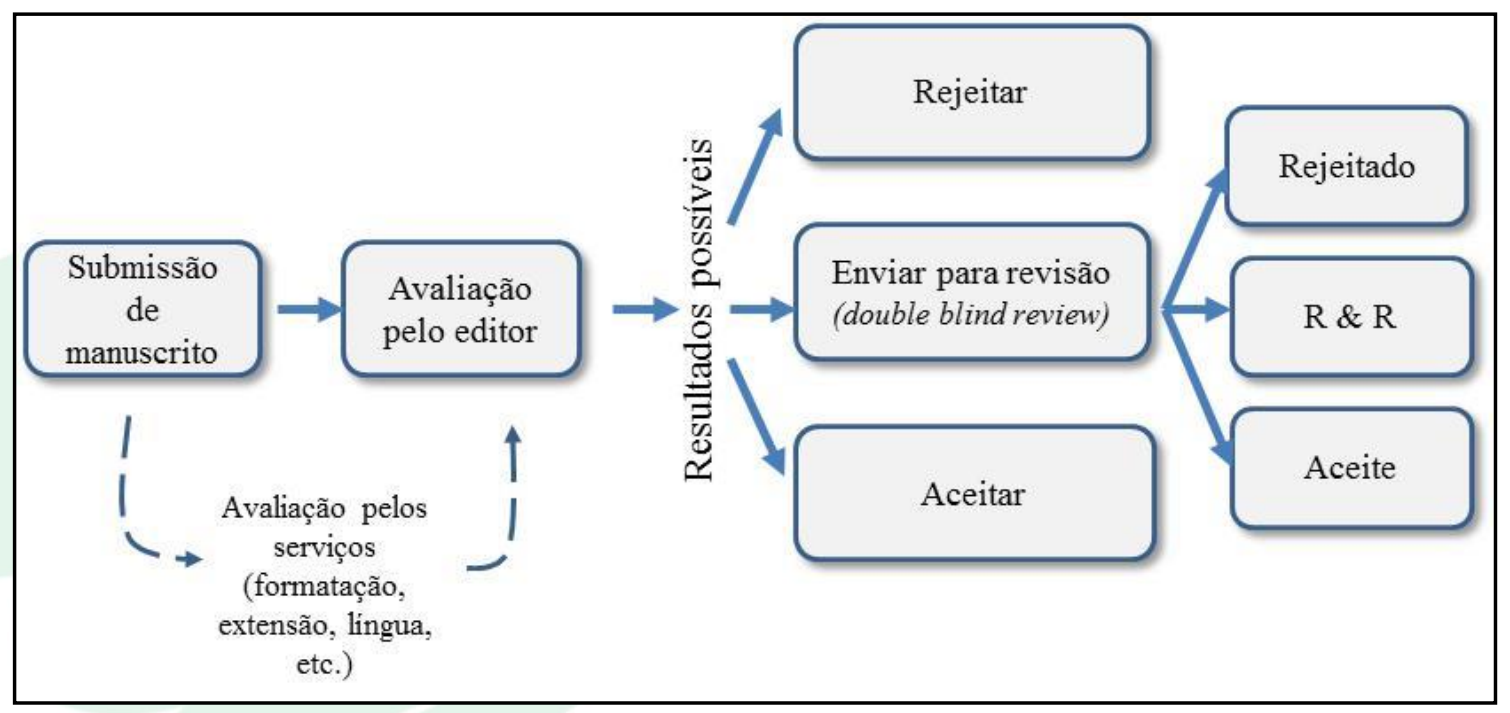

Fonte: Elaborado pelo autor.

O segundo desfecho, com alto grau de probabilidade, é que o editor decida por rejeitar o artigo. Por exemplo, no Brasil, um editorial de 2013 do Professor Eduardo Diniz, Editor Chefe da Revista de Administração de Empresas (RAE) dava conta da situação específica. Na RAE, em 2012, 57\% dos artigos submetidos não passou a fase de escrutínio inicial, tendo sofrido um desk reject. e apenas $5 \%$ dos artigos submetidos ao periódico passaram à etapa do double blind review. $\mathrm{O}$ editor pode rejeitar o artigo imediatamente por vários motivos como seja: por o artigo não se enquadrar na missão ou foco da revista ou porque, na opinião do editor, o manuscrito não tem qualidade suficiente para ser enviado para revisores (em outro artigo tratarei as questões dos revisores, incluindo como responder a carta dos revisores), por erros que identifica na sua leitura ou até por a revista ter publicado recentemente artigo sob tema idêntico. Designamos a rejeição imediata pelo Editor como desk rejection. Todos os periódicos têm esta fase ainda que a exigência 
envolvida nesta avaliação pelo Editor possivelmente será tão maior quanto o estatuto do periódico. Se o manuscrito for rejeitado, o Editor informa o autor que pode então submeter a outro periódico. Caso o Editor tenha dado alguns comentários e sugestões é preferível ver se são possíveis incorporar antes de uma nova submissão.

O terceiro desfecho é o Editor considerar que o manuscrito tem mérito suficiente e decidir enviar o manuscrito para avaliação por pares. Designamos por pareceristas ou revisores (referees). Usualmente, escolherá dois ou três avaliadores a quem solicitará uma análise, dará alguma indicação sobre as práticas e expectativas da revista (ou apenas um formulário de avaliação) e um período de tempo para a avaliação ser devolvida (Tight, 203). A prática vigente é que este processo decorra em sistema de double blind review - para evidenciar que nem o autor sabe quem é o avaliador, nem o avaliador sabe quem é o autor. Garante-se, assim, a imparcialidade que relações pessoais ou o status relativo de alguns autores poderiam levar o avaliador a aceitar para publicação trabalhos que não cumprem os requisitos de qualidade desejáveis. Ou seja, o Editor escolhe para revisor do manuscrito submetido outros pesquisadores que têm conhecimento na área especifica do manuscrito que foi submetido.

\section{O PAPEL DOS REVISORES E O QUE EFETIVAMENTE FAZEM}

O principal papel dos revisores é avaliar criticamente um manuscrito que lhes é remetido. A convicção é que o processo de revisão ajuda a melhorar a qualidade final dos trabalhos publicados. Assim, idealmente, os revisores proporcionarão aos autores sugestões e comentários construtivos, numa revisão concluída dentro do prazo solicitado, e que seja imparcial, correta, educada e não hostil (Bedeian, 2003, Miller, 2006). Com frequência os periódicos dispõem do seu próprio manual de boas práticas para os revisores.

Os revisores recebem um formulário onde farão a avaliação juntamente com o manuscrito e o convite para fazerem a avaliação do manuscrito. Este formulário tem, frequentemente, duas partes principais: uma itemizada e outra para escrita livre. A de escrita livre pode ser direcionada para os itens ou simplesmente é um campo livre onde o revisor faz a sua análise, comentários e sugestões. Na parte itemizada é comum que os itens foquem uma avaliação do manuscrito quanto à qualidade de: interesse do tema para a área (no fundo é adequação ao periódico), formulação da questão de pesquisa ou problema de investigação, clareza do objetivo, qualidade da revisão da literatura, rigor metodológico (procedimentos, amostra, variáveis), análise dos resultados, organização do 
manuscrito e fluidez dos argumentos, discussão e contribuição. O formulário termina solicitando uma recomendação final onde as opções se dividem em: (1) aceitar na presente forma, (2) aceitar com revisões menores, (3) rever e resubmeter para nova avaliação e (4) rejeitar. Numa carta separada, e que não será divulgada ao autor, o revisor é convidado a, brevemente, expor a sua avaliação ou o porquê da recomendação final.

A análise pelos revisores é muitas vezes mal entendida e até criticada por castrar a criatividade dos pesquisadores, mas é o processo que existe (Beyer, Chanove \& Fox, 1995; Miller, 2006; Tsang \& Frey, 2007). Alguns autores referem-se ao processo de revisão como prostituição (Frey, 2002) na medida que são impostas ao autor preferências subjetivas que este tem de acolher dos comentários dos revisores eventualmente perdendo a sua originalidade (Tsang \& Frey, 2007). Outros, ainda, referem-se a censura (Casadevall, \& Fang, 2009). E, há evidência que a qualidade do processo de revisão pelos pares não é completamente fiável (Garfunkel et al., 1990). Em experimentos alguns estudos analisaram como artigos aceites e já publicados em periódicos foram avaliados e muitas vezes rejeitados quando submetidos a nova avaliação (ver, por exemplo, Garfunkel et al., 1990). De fato, a avaliação é sempre subjetiva pelo que acontece que para o mesmo artigo dois ou três avaliadores possam formular julgamentos bastante díspares. Por exemplo, em três avaliadores, um pode recomendar aceitar o artigo, outro sugerir alterações e o terceiro rejeitar. Cumpre sempre ao editor analisar os pareceres e formular uma resposta sobre o seguimento do artigo no processo. Ainda assim, o objetivo do processo é melhorar a qualidade dos artigos publicados (Miller 2006; Macdonald \& Kam 2007, 2008).

Como se observa na figura, esta etapa pode resultar em os avaliadores darem uma de três respostas: o artigo é aceito para publicação sem mais alterações (o que sinceramente é um cenário pouco realista), o artigo deve ser rejeitado (muito provável) ou o artigo merece a oportunidade de uma revisão - que precisará seguir as recomendações e sugestões proporcionadas pelos avaliadores. Evidentemente, neste último caso, se o autor decidir fazer as alterações resubmeterá o artigo ao periódico para nova avaliação pelos mesmos pareceristas e novamente o desfecho conterá uma das três situações: aceite, rejeitado ou R\&R (rever e resubmeter). Não é comum um artigo cumprir três rondas de revisão para uma rejeição no final.

Concluo esta seção com a nota que muitos editores convidam para revisores dos artigos os acadêmicos mais reputados - obviamente, o corpo editorial de um periódico é também um sinal do seu estatuto. No entanto, há alguma evidência que a qualidade do trabalho de revisão varia inversamente com a senioridade e status do próprio avaliador (Stossel, 1985; Finke, 1990; Judson,

Revista Ibero-Americana de Estratégia - RIAE, São Paulo, v. 12, n. 3, p. 01-11, jul./set. 2013. 
1994). Naturalmente os mais seniores tenderão a desempenhar inúmeras outras funções e terem menos tempo para o trabalho de revisão. O fato é que o trabalho de revisão no Brasil é ainda altruísta e a única compensação é o senso de serviço, ainda que alguns notem o benefício de aceder ao mais novo conhecimento (Laband, 1990).

\section{A REJEIÇÃo}

Como referi acima, qualquer aceitação é motivo para celebração. Mas, quando falamos de taxas de rejeição dos periódicos, de que valores estamos a falar? Importa começar por esclarecer que a taxa de rejeição será tão maior quanto maior for a qualidade (ou ranking) do periódico. Infelizmente poucos periódicos disponibilizam estas informações. Sabemos, no entanto, que em periódicos internacionais de maior reputação as desk rejections podem ser de 40, 50, 60\% ou superiores. Por exemplo, no Quarterly Journal of Economics foi de 62\% em 2011, e uma nota editorial de 2005 do Academy of Management Journal notou que em 2004 a taxa de desk rejects era de $30 \%$ e podemos supor que atualmente seja bastante superior. As taxas de rejeição totais, incluindo aqui os manuscritos que passam por revisão mas acabam não sendo aceites para publicação, atingem valores muitas vezes próximos dos 90\% (Clark et al., 2006). Ou seja, feitas as contas, mais de $95 \%$ dos artigos submetidos aos melhores periódicos serão rejeitados. A rejeição é, portanto, a norma!

Mas, porque os artigos são rejeitados? Quais as suas principais debilidades? Tratarei este aspecto em maior detalhe em futuro comentário editorial, mas noto que o próprio processo editorial pode impactar no desfecho. Sendo a avaliação pelos pares sempre subjetiva, poderá haver questões menos científicas como as questões de gosto, de interesse, de ponto de vista conceitual, que diferindo entre o autor e algum revisor conduz ao desfecho da rejeição. Há inúmeros mitos envolvendo a publicação e, também, algumas verdades. As verdades, apesar da ausência de evidência estatística fiável, é que fatores como ter um "nome importante" ajuda a publicar e conhecer bem o Editor também. No entanto, note que os acadêmicos não desenvolvem um bom nome para si sem que antes tenham feito o trabalho. Ou seja, o bom nome é como uma marca que sinaliza não apenas a qualidade do produto mas também, no caso dos artigos, a capacidade de eficazmente fazer as alterações no manuscrito que satisfarão os revisores. Assim, em caso de dúvida é provável que o editor mais facilmente conceda a possibilidade de revisão a um "nome importante" que a um jovem doutorando. 
O Processo Editorial: da Submissão à Rejeição (ou Aceite)

Um mito talvez mais impactante para a publicação internacional, em especial nos países onde a língua não é o inglês, é que as carências na língua impossibilitam a publicação. Um estudo de Ehara e Takahashi (2007) sobre as taxas de rejeição analisou a origem geográfica e língua materna dos autores que submeteram ao AJR e concluiu que a taxa de aceitação quando os autores têm inglês como primeira língua $(40,3 \%)$ é maior que quando não têm $(29,1 \%)$, mas que as barreiras linguísticas não foram a principal razão para a rejeição (exceto para manuscritos oriundos da China). As debilidades ao nível da contribuição e geração de novo conhecimento foram a principal razão apontada para a rejeição independentemente da língua (44 a $76 \%$ de todas as rejeições). Outras deficiências fundamentais incluíram erros metodológicos, erros na análise de dados, artigos mal escritos, etc. Os problemas com a língua foram apenas o $13^{\circ}$ fator identificado como potencialmente levando à rejeição. Efetivamente, um relatório.

\section{NOTAS FINAIS}

Entender com decorre o processo de submissão dentro dos periódicos é importante para os autores. Provavelmente poucos autores gostarão de receber e ler cartas de rejeição dos Editores, pelo que este comentário editorial tem quatro objetivos: primeiro, dar a conhecer o processo a jovens profissionais que chegaram à pouco ao meio acadêmico. Segundo, pretende pelo menos minimizar a probabilidade de ter rejeições. Terceiro, que uma rejeição não conduza à desmoralização para pesquisas futuras. E, por quarto, contribuir para melhorar o processo. Não há novos "insights" que possa partilhar para conseguir publicar em periódicos de topo exceto: planear o trabalho de pesquisa antes de o começar a fazer, siga as normas do trabalho científico, muita atenção à escrita (incluindo aqui a forma como as frases são escritas e os parágrafos organizados), e muito empenho nas sucessivas revisões do manuscrito antes de submeter. Embora não seja nada de novo, é sempre bom recordar que a contribuição (o novo conhecimento gerado e sua utilidade) é, possivelmente, um dos aspectos que merecem ser intensamente trabalhados antes de submeter a um periódico internacional de elevada estatura.

O processo editorial assenta em alguns mitos e idéias que se tornam crescentemente condições sine qua non para a publicação (Samkin, 2011). Por exemplo, que há uma forma e uma medida exata passível de utilização na avaliação dos artigos. Também que todos os revisores são profissionais dedicados e empenhados na sua contribuição para a ciência, pelo que empenharão o

Revista Ibero-Americana de Estratégia - RIAE, São Paulo, v. 12, n. 3, p. 01-11, jul./set. 2013. 
seu melhor esforço em cada avaliação lhes solicitada. A realidade é que muitos Professores têm agendas bem preenchidas entre os requisitos de intervenção na comunidade, o ensino, as funções administrativas, a orientação de alunos, a sua própria pesquisa e, para alguns, uma vida pessoal. O domínio da língua inglesa como o mais válido veículo para comunicar conhecimento; eliminando os pesquisadores que não tenham tido a sorte de nascer num país anglo-saxónico, porque só aí reside a verdade. A capacidade de os revisores avaliarem qualquer manuscrito quanto à qualidade da exposição escrita, dado que são eles próprios excepcionais escritores.

Conhecer e saber como navegar todo o processo que vai da submissão à resposta aos revisores em cada ronda de revisão do manuscrito (assunto que também abordarei em detalhe noutro comentário editorial, pela importância que a etapa de resposta aos revisores tem) é crucial para ter sucesso. O sucesso aqui é medido pela publicação. O desenvolvimento cuidado de um artigo é fundamental mas não é garantia de publicação. Há um elemento que Samkin (2011) chama de loteria, porque existe sempre um elemento de sorte em todo o processo como seja a sorte de ter revisores que partilhem a nossa perspectiva, que acompanhem as nossas alterações ou compreendam a impossibilidade de atender a todas as sugestões, a sorte de ter um revisor que efetivamente se dedique à avaliação. Mas, a sorte começa antes da submissão, no planejamento cuidado da pesquisa, no pensamento crítico das hipóteses, na coleta de dados, no levantamento exaustivo da literatura, na análise escrupulosa dos resultados, etc. Mas, publicar consistentemente em periódicos bem reputados não é uma questão de sorte. A capacidade e persistência acabarão por derrotar a má sorte. 
O Processo Editorial: da Submissão à Rejeição (ou Aceite)

\section{REFERÊNCIAS}

Baumeister, R. Dear journal editor, it's me again, American Journal of Roentgenology, 158: 915-, 1992.

Bedeian, A. The manuscript review process: The proper roles of authors, referees, and editors, Journal of Management Inquiry, 12(4): 331-338, 2003.

Beyer, J., Chanove, R. \& Fox, W. The review process and the fates of manuscripts submitted to the AMJ, Academy of Management Journal, 38(5): 1219-1260, 1995.

Casadevall, A. \& Fang, F. Is peer review censorship?, Infection and Immunity, 77(4): 1273-1274, 2009.

Clark, T, Floyd, S. \& Wright, M. On the review process and journal development, Journal of Management Studies, 43(3): 655-664, 2006.

Diniz, E. Editorial, Revista de Administração de Empresas, 53(1): 1.

Ehara, S. \& Takahashi, K. Reasons for rejection of manuscripts submitted to AJR by international authors, American journal of Roentgenology, 188: W113-W116, 2007.

Finke, R. Recommendations for contemporary editorial practices. American Psychologist, 45: 669670, 1990.

Frey, B. Publishing as prostitution? Choosing between one's own ideas and academic success. Public Choice, 116: 205-223, 2002.

Garfunkel, J., Ulshen, M., Hamrick, H. \& Lawson, E. Problems identifíed by secondary review of accepted manuscripts. Joumal of the American Medical Association, 263:1369-1371, 1990.

Hojat, M., Gonnella, J. \& Caelleigh, A. Impartial judgment by the "Gatekeepers" of science: Fallibility and accountability in the peer review process, Advances in Health Sciences Education, 8(1): 75-96, 2003.

Judson, H. Structural transformations of the sciences and the end of peer review. Journal of the American Medical Association, 212: 92-94, 1994.

Laband, D. Is there value-added from the review process in economics? Preliminary evidente from authors. Quarterly Joumal of Economics, 105: 341-352, 1990. 
Macdonald, S. \& Kam, J. Quality journals and gamesmanship in management studies, Management Research News, 31(8): 595-606, 2008.

Macdonald, S. \& Kam, J. Ring a ring o' roses: quality journals and gamesmanship in management studies, Journal of Management Studies, 44(4): 640-655, 2007.

Miller, C. Peer review in the organizational and management sciences: Prevalence and effects of reviewer hostility, bias and dissensus, Academy of Management Journal, 49(3): 425-430, 2006.

Samkin, G. Academic publishing: A faustian bargain?, Australasian Accounting Business and Finance Journal, 5(1), 19-34, 2011.

Shugan, S. Editorial: The mission of Marketing Science. Marketing Science. 21(1): 1-13, 2002.

Shugan, S. The editor's secrets, Marketing Science, 26(5): 589-595, 2007.

Starbuck, W. How much better are the most-prestigious journals? The statistics of academic publication. Organization Science, 16(2): 180-202, 2005.

Stossel, T. Reviewer status and review quality: Experience of the Joumal of Clinical Investigution. New England Joumal of Medicine, 312: 1658-1659, 1985.

Tight, M. Reviewing the reviewers, Quality in Higher Education, 9(3): 295-303, 2003.

Tsang, E. \& Frey, B. The as-is journal review process: Let authors own their ideas. Acad. Management Learning Education, 6(1): 128-136, 2007.

Van Teijlingen, E. \& Hundley, V. Getting your paper to the right journal: A case study of an academic paper, Journal of Advanced Nursing, 37(6): 506-511, 2002.

Van Wyk (1998) Publish or perish: A system and a mess. System Practice and Action Research, 11(3): 247-259, 1998.

Recebido: 21/05//2013

Aprovado: 20/07/2013 